УДК: 330.59

DOI: 10.14451/1.191.64

\title{
РАЗВИТИЕ МУЛЬТИСЕРВИСОВ КАК ФАКТОР ПОВЫШЕНИЯ КАЧЕСТВА ЖИЗНИ НАСЕЛЕНИЯ
}

\author{
(C) 2020 Домнин Антон Дмитриевич \\ аспирант, Высшая инженерно-экономическая школа \\ Санкт-Петербургский политехнический университет Петра Великого (СПбПУ), \\ Россия, Санкт-Петербург \\ E-mail: domnin_a@mail.ru \\ (C) 2020 Барыкин Сергей Евгеньевич \\ доктор экономических наук, профессор, Высшая школа сервиса и торговли \\ Санкт-Петербургский политехнический университет Петра Великого (СПбПУ), \\ Россия, Санкт-Петербург \\ E-mail: sbe@list.ru
}

В числе индикаторов качества жизни населения страны, региона находятся показатели потребления услуг, в том числе оказание бытовых услуг населению. Рост их потребления специалисты в области управления связывают с ростом доходов населения, увеличением свободного времени, комфортностью проживания. Значимость увеличения предложения качественных бытовых услуг, развития сети предприятий бытового обслуживания в городской и сельской местностях, недостаточная разработанность методического обеспечения внутреннего контроля качества бытовых услуг, необходимость использования новых организационных форм взаимодействий исполнителей и потребителей бытовых услуг, а также муниципальных и региональных органов управления и контроля, обусловили актуальность темы статьи. В статье рассмотрена концепция бытового мультисервиса как многопрофильного комплекса предприятий или индивидуальных предпринимателей, оказывающих бытовые услуги населению и располагающихся в пределах шаговой доступности друг от друга.

Ключевые слова: бытовое обслуживание населения, бытовые услуги, бытовой мультисервис

\section{Введение}

Бытовое обслуживание населения, имеющее длительную историю развития в советский период развития Российской Федерации, подверглось серьезным деформациям в период реформ 90-х годов XX века. Данный вид деятельности, имеющий социальное значение, характеризуется невысокой рентабельностью, преимущественно индивидуальным характером обслуживания потребителей услуг, незначительными объемами прибылей, не привлекал внимание предпринимателей в период становления рыночных отношений. В результате значительно сократилась сеть предприятий бытового обслуживания населения, была практически разрушена инфраструктура отрасли.

$\mathrm{K}$ настоящему времени подавляющая часть предприятий бытового обслуживания являются малыми, бытовые услуги оказывает значительное количество индивидуальных предпринимателей. Отсутствие серьезной поддержки малого предпринимательства в стране, необходимость для предпринимателей решения проблем арен- ды, пополнения оборотных фондов, расчетов с поставщиками в условиях инфляции издержек, отодвигает для них проблемы качества на второй план. Это является недопустимым, особенно в отношении бытовых услуг, которые относятся к социально значимым. Восстановление контрольных механизмов в отрасли выражается в работе с потребителями на неудовлетворительное качество полученных услуг, однако проблема предотвращения низкого качества услуг в современных условиях организации бытового обслуживания в стране пока не решена. В то же время и ученые-теоретики, и специалисты-практики отмечают необходимость и возможность внедрения в практику предприятий бытового обслуживания населений инструментов и методов, позволяющих осуществлять мониторинг и регулирование качества бытовых услуг. Столь же важным является решение задачи определения организационных форм взаимодействия сторон, заинтересованных в обеспечении населения качественными бытовыми услугами, включая органы местного и регионального управления. 
Формирование подхода к управлению качеством услуг бытового обслуживания

До настоящего времени не выработано объективных методов оценки качества бытовых услуг. Практически все методы основаны на субъективных факторах, связанных с ожиданиями потребителя и его фактическими впечатлениями, удовлетворенностью от получения услуги. Расхождение между желаемой и фактической оценкой услуги и является оценкой ее качества потребителем [2, 8].

Оценка качества услуги ее производителем производится на основе оценки ее соответствия ряду критериев, установленных законодательно либо на основе корпоративных стандартов [4, 7].

Управление качеством услуг начинается с планирования соответствующих мероприятий. Планирование качества услуг для определенного периода деятельности или на некоторую определенную дату в общем виде означает обоснование количественных и качественных показателей, определяющих их характеристики $[1,5,13$, 20]. Следовательно, планирование мероприятий по контролю качества услуг и его повышению должно базироваться на обоснованных прогнозах нужд потребителей, детализированных по их предпочтениям и ожиданиям относительно определенной бытовой услуги [3, 6, 16].

После того, как разработаны планы, устанавливающие задания по объемам, ассортименту и качеству услуг, реализуются процессы организации, мотивации, регулирования и координации, которые обеспечивают возможность [12, 15, 18]:

- своевременной и эффективной реализации плановых мероприятий по обеспечению соответствия фактического качества услуг государственным, отраслевым и корпоративным стандартам;

- оперативной реакции служб, подразделений и специалистов на претензии потребителей к качеству полученной услуги.

Несоответствие фактических характеристик бытовой услуги ожиданиям потребителя может возникать вследствие действия технических, организационных, экономических и социальных факторов.

\footnotetext{
Факторы важности бытового обслуживания

С целью определения степени социальной значимости отдельных видов бытовых услуг на основе проведенного Региональной ассоциаци-
}

ей предприятий мультисервиса анкетирования заказчиков [14] были выявлены услуги, относимые населением к социально значимым, и в том числе для низкодоходных категорий населения. Это услуги парикмахерских, по ремонту обуви, ритуальные, ремонту и техническому обслуживанию бытовой радиоэлектронной аппаратуры, услуги бань и фотографий, ремонту бытовой техники и автомобильного транспорта. Однако, несмотря на высокую социальную значимость выявленных услуг, не все они доступны для потребителя, особенно для незащищенных категорий населения [9]. Такая ситуация объясняется целым рядом причин, наиболее важными из них являются: высокий уровень цен; отсутствие предприятий во многих городах и районах; территориальная недоступность предприятий; неудобный режим работы предприятий; низкое качество предоставляемых услуг; низкий уровень обслуживания.

Проведенный анализ позволяет сделать вывод, что в результате трансформационных процессов в сфере бытового обслуживания к настоящему моменту определились четыре основные группы хозяйствующих субъектов[9]:

- индивидуальные предприниматели, на долю которых приходится 40\% общего объема услуг;

- малые предприятия, сохранившие традиционные формы организации бытовых услуг, они оказывают всего лишь 6\% объема бытовых услуг области;

- непрофильные предприятия и организации, которые кроме своей основной деятельности участвуют в оказании бытовых услуг населению. На их долю приходится 47\% общего объема бытовых услуг.

- профильные предприятия службы быта, оказывающие около 7\% общего объема услуг.

По сравнению с материальным производством сфера бытовых услуг имеет ряд особенностей, в частности, в силу специфики повышение качества услуг, как правило, сопровождается увеличением ресурса затрат. Кроме этого, эта сфера испытывает сильные воздействия социальнодемографических процессов, а также целого ряда факторов, связанных с денежными доходами и расходами населения. На развитие сферы бытового обслуживания оказывает влияние динамика воспроизводства домашнего и личного хозяйства $[11,17]$.

Ученые экономисты, исследуя проблемы раз- 
вития жилого фонда крупных городов выделяют факторы, которые помимо качества самого жилья определяют и его цену. Н.В.Иванова [14] выделила и проранжировала семь таких факторов в соответствии с коэффициентом относительной важности $(K O B)$. Наибольшее значение $К O B$ для данной выборочной совокупности получил фактор транспортной доступности $(K O B=0,298)$. На втором месте оказался фактор уровня развития социально-бытовой инфраструктуры $(K O B=0,167)$. Далее следуют экологический фактор, престижность района, характер окружающей застройки, административное деление территории и социальный статус населения. Таким образом, ориентиры потребителей подтверждают необходимость развития социально-бытовой инфраструктуры города [10].

Обоснование бытового мультисервиса как фактора повышения качества жизни населения

Немалый вклад в экономику города может внести новая организационная форма кооперирования предприятий социально-бытового обслуживания с объектами досуга и торговли мультисервисы. Практика показывает, что мультисервисы как торгово-развлекательные комплексы встречаются не только в крупных, но и в средних и малых городах России и являются одним из основных видов активов территориального образования. В едином здании располагаются такие учреждения досуга и оборудование для него, как фитнес-клубы, игровые автоматы, боулинг, кегельбаны, кино- и спортивные залы, торговые центры, бары, рестораны, а также различные туристические и транспортные агентства, бюро и пр. Все они являются, как правило, высокорентабельными и, следовательно, привлекательными для инвесторов. Предприятия бытового обслуживания значительно уступают им в рентабельности, в результате чего многие из них, не выдержав конкурентной борьбы, прекратили свое существование $[10,19]$.

Бытовой мультисервис - это многопрофильный комплекс предприятий или индивидуальных предпринимателей, оказывающих бытовые услуги населения и располагающихся в пределах шаговой доступности друг от друга. Набор услуг, оказываемых бытовым мультисервисом, определяется на основании маркетингового исследования. На выбор видов бытовых услуг влияют следующие факторы: демографический состав населения, живущего и работающего в районе, платежеспособный спрос на различные виды услуг, наличие объектов массового посещения, транспортные магистрали, радиус обслуживаемой территории и др.

Муниципальные органы власти должны обратить серьезное внимание на комплексное развитие территорий, особенно в окраинных районах мегаполисов. Они обязаны в большей степени оказывать практическую помощь при создании мультисервисов как новой организационной формы бытового обслуживания и содействовать строительству и реконструкции зданий для кооперированных учреждений и предприятий бытового обслуживания и досуга.

Целесообразно размещение бытового мультисервиса на территории торговоразвлекательных комплексов, имеющих подземные паркинги (что необходимо для размещения автосервиса). Примерная схема взаимодействий предпринимателей, региональных и муниципальных органов власти при создании мультисервиса представлена на рисунке 1.

Размещение бытового мультисервиса на площадях торгово-развлекательных комплексов имеет, по мнению автора монографии следующие преимущества:

- население региона получает возможность одновременного доступа к широкому ассортименту услуг: бытовых, торговых, развлекательных туристских и пр.;

- увеличивается проходимость ателье, салонов и приемных пунктов предприятий бытового обслуживания, торговых точек за счет высокой посещаемости торгово-развлекательных комплексов;

- владельцы малых предприятий бытового обслуживания и индивидуальные предприниматели, оказывающие бытовые услуги и являющиеся членами бытового мультисервиса на территории торгово-развлекательного комплекса.

Членство в координационном совете арендаторов-предприятий БОН (бытового обслуживания населения) является обязательным и должно быть включено в условия арендного договора. Высокое качество предоставления бытовых услуг, так же, как и их комплексность соответствует интересам арендодателя - собственника помещений торгово-развлекательного комплекса, поскольку оно способствует увеличению количества посещений, росту доходов арендаторов и, вследствие этого, создает возможность беспере- 


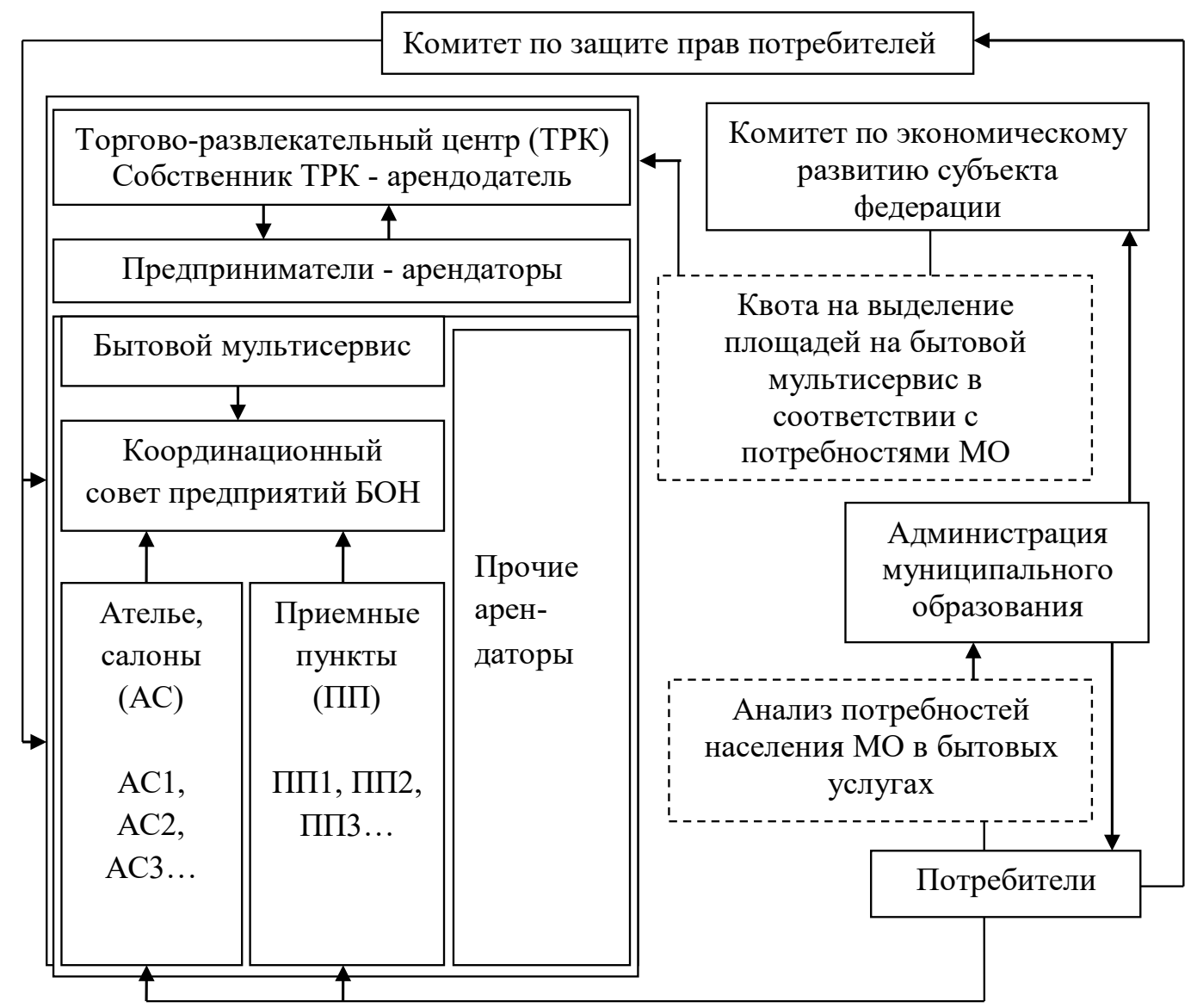

Рисунок 1. Схема взаимодействия предпринимателей и органов регионального и муниципального управления при создании бытового мультисервиса [10].

бойного поступления арендной платы.

Общее собрание членов бытового мультисервиса создает координационный совет и принимает Положение об организации контроля качества бытовых услуг в мультисервисе. Данное положение должно предусматривать создание открытой системы менеджмента качества всеми членами мультисервиса, что предполагает согласие на проведение периодических проверок качества оказываемых услуг, а также на участие представителей членов мультисервиса при выявлении причин и ликвидации последствий жалоб потребителей на оказанную услугу конкретным участником мультисервиса.

Координационный совет создает комиссию по контролю качества услуг, в состав которой входят представители предпринимателей членов бытового мультисервиса. Комиссия осуществляет свою работу на основе соблюдения следующих принципов [14]:

- соблюдение требований нормативно-правовых документов, регламентирующих предпринимательскую деятельность и качество бы- товых услуг населению;

- осуществление контрольных мероприятий только при участии всех членов комиссии, уполномоченных на их проведение;

- установление перечня требований, обязательных для членов мультисервиса при оказании ими бытовых услуг на территории мультисервиса в строгом соответствии с федеральными законами, постановлениями региональных органов власти;

- непрерывность одного контрольного мероприятия;

- объективность и беспристрастность при установлении причин появления жалоб потребителей;

- возможность обжалования действий и решений комиссии по контролю качества услуг, нарушающих действующие нормы права, условия арендного договора или Положения об организации контроля качества бытовых услуг в мультисервисе, в координационном совете мультисервиса, государственных органах надзора и контроля; 
- недопустимость взимания платы с членов мультисервиса за проведение контрольных мероприятий за исключением случаев возмещения расходов на проведение экспертиз качества услуг;

- персональная имущественная, дисциплинарная и уголовная ответственность должностных лиц органов государственного контроля за нарушение законодательства Российской Федерации.

В рамках государственной целевой программы поддержки отечественных изготовителей товаров, Региональная Ассоциация Мультисервиса совместно с Российским Государственным Университетом Туризма и Сервиса (РГУТиС), в целях реализации Постановления Правительства Москвы № 25-ПП от 20.01.2009 года «О совершенствовании комплексного обслуживания населения в сфере потребительского рынка и услуг в городе Москве» [21], предложила концептуальную идею типового объемно-модульного здания с применением малозаглубленных фундаментов для размещения предприятия бытовых услуг, функционирующего по типу «мультисервис».

Авторы концепции основываются на возрождении «Домов быта», распространенных в советский период развития России, на современной технологической основе. Предлагаемые ими к внедрению «Центры-мультисервисы» расположены в отдельно стоящих зданиях, построенных по типовым проектам объемно-модульного здания. Авторы проекта справедливо указывают, что традиционная для сферы бытового обслуживания социальная ориентация и стабильный спрос заказчиков на бытовые услуги, конечно, создают для «Центров-мультисервиса» наиболее благоприятные условия по сравнению с предприятиями бытового обслуживания узкой специализации.

\section{Заключение}

Бытовые услуги относятся к социально значимым видам услуг, однако их потребление группой населения с наиболее высокими доходами в России растет быстрее, чем группой наименее обеспеченного населения. Поэтому среди приоритетных задач органов территориального управления является стимулирование развития тех форм предпринимательской деятельности, которые обеспечивают предоставление быто- вых услуг, удовлетворяющих наименее обеспеченные слои населения по соотношению цена/ качество. Для этого необходимо как развитие конкуренции среди предпринимателей, так и создание условий для постоянного контроля качества, удовлетворения жалоб потребителей и их предотвращения.

Проблемы качества бытовых услуг, отмеченные экспертами, могут быть решены на основе объединения предпринимателей в саморегулируемые организации - ремесленные палаты по каждому профилю бытовых услуг, взаимодействующие с администрациями муниципальных округов. Представляется целесообразным организовать в субъекте федерации десять ремесленных палат по направлениям бытовых услуг, каждая из которых возглавляется координационным советом, разрабатывающим и выносящим на утверждение общим собранием членов СРО-ремесленной палаты стандарты профессиональной деятельности и стандарты оказания бытовой услуги.

Основываясь на солидном практическом опыте Региональная Ассоциация Мультисервиса предложила следующий порядок организация мультисервиса. Во-первых, необходимо определить место размещения мультисервиса. В крупных городах, где осуществляется массовая застройка микрорайонов, а ввод жилых домов осуществляется поэтапно, типовое объемномодульное здание для размещения предприятия бытового обслуживания по типу «мультисервис» позволяет обеспечить запросы жителей в услугах, до момента организации стационарных предприятий сферы услуг.

Второй целью является формирование современной инфраструктуры пешеходной (шаговой) доступности в целях формирования комфортных условий проживания в соответствии со стандартами качества жизни. Следующей целью является поддержка отечественного изготовителя современных строительных конструкций.

Безусловно, предложения РАМС и РГУТиС несущественно отличаются от концепции советских Домов быта. Кроме того, строительство малоэтажных мультисервисов в крупных городах, где цена земли чрезвычайно высока, экономически неоправданно. Комплексность предоставления услуг потребителю при размещении бытовых мультисервисов в торгово-развлекательных комплексах существенно выше. 


\section{Библиографический список}

1. Akhmetshin Е.M. [и др.]. Internal control system in enterprise management: Analysis and interaction matrices 2018.

2. Dahlgaard J. J., Khanji G. K., Kristensen K. Fundamentals of total quality management / J. J. Dahlgaard, G. K. Khanji, K. Kristensen, Routledge, 2008.

3. Goetsch D.L., Davis S.B. Quality management for organizational excellence / D. L. Goetsch, S. B. Davis, pearson Upper Saddle River, NJ, 2014.

4. Hoyle D. Quality management essentials / D. Hoyle, Routledge, 2007.

5. Kaynak $H$. The relationship between total quality management practices and their effects on firm performance // Journal of operations management. 2003. № 4 (21). C. 405-435.

6. Saraph J.V., Benson P. G., Schroeder R.G. An instrument for measuring the critical factors of quality management // Decision sciences. 1989. № 4 (20). C. 810-829.

7. Wang R.Y. A product perspective on total data quality management // Communications of the ACM. 1998. № 2 (41). C. 58-65.

8. Zbaracki M.J.The rhetoric and reality of total quality management // Administrative science quarterly. 1998. C. 602-636.

9. Герасимов Б.И. [и др.]. Научно-методические основы развития интегрированных систем менеджмента качества предприятий и организаций // Вестник Тамбовского университета. Серия: Гуманитарные науки. 2015. № 4 (144).

10. Горовой А.А. Методология территориальной организации интегрированных объектов социальной инфраструктуры региона: дис.. д-ра экон. наук // 2015.

11. Егорихина М. С., Шамин Е. А. Особенности развития современного рынка бытовых услуг // Азимут научных исследований: экономика и управление. 2018. № 2 (23) (7).

12. ЗаборовсКИЙ Д.А. НЕКОТОРЫЕ ОСОБЕННОСТИ УПРАВЛЕНИЯ КАЧЕСТВОМ ОБРАЗОВАНИЯ В сборнИКе: АЛЬманах научных работ молодых ученых Университета ИTMO. XLVII научная и учебно-методическая конференция Университета ИТМО. 2018. С. 33-35.

13. ЗаборовсКИй Д.А. НЕОБХОДИМОСТЬ СОВЕРШЕНСТВОВАНИЯ УПРАВЛЕНИЯ КАЧЕСТВОМ НА ВАГОНОРЕМОНТНОМ ПРЕДПРИЯТИИ 2017.С. 86-88.

14. Иванова Н. В. Развитие социально-бытовой инфраструктуры мегаполисов: строительство и реконструкция мультисервисов // «Недвижимость: экономика, управление».- № 7-8.-2004.- c.24-27.

15. Невмывако В.П. Обеспечение экономической устойчивости предприятий путем оптимизации системы управления качеством услуг // Экономика и социум: современные модели развития. 2018. № 2 (8). С. 22-32.

16. Никулина Ю. Н., Вакушкина О.И. Повышение конкурентоспособности организации сферы услуг с позиции системы управления качеством // Universum: экономика и юриспруденция. 2017. № 3 (36).

17. Окрепилов В.В. Менеджмент качества: учебник // СПб.: Изд-во Политехн. ун-та. 2013.

18. ПАСБКО О. В., ДУСЕНКО С.В.Управление качеством услуг организации питания в индустрии гостеприимства // Стандарты и качество. 2016. № 10. С. 74-79.

19. СЮТКИН Г. Н. МУЛЬТИСЕРВИС КАК ЭФФЕКТИВНАЯ ФОРМА ОРГАНИЗАЦИИ СФЕРЫ УСЛУГ // ВЕСТНИК АКАДЕМИИ. 2012. № 4. С. 131-135.

20. Тимофеев Д. А., Кожанова В.А., Семчугова Е.Ю. Особенности системы управления качеством предоставляемых услуг // Международный научный журнал Инновационная наука. 2018. № 01. С. 35-37.

21. Постановление Правительства Москвы от 20 января 2009 г. N 25-ПП «О совершенствовании комплексного обслуживания населения в сфере потребительского рынка и услуг в городе Москве». 